\title{
A New PV-SOFC based Hybrid topology Using PI Controller for the Regulation of Voltage and Frequency Profile in an Autonomous Microgrid
}

\author{
V.P. Vinod, N. Albert Singh*
}

\begin{abstract}
This paper proposes a new, reliable and efficient microgrid structure which incorporates PV arrays and SOFC interconnected via Voltage Source Inverter (VSI) as an alternative to reduce the detrimental impact of energy generation on atmosphere using fossil fuels. Inorder to meet the growing energy demands, the excessive usage of nonrenewable energy resources disregarding the environmental impacts resulted in major environmental problems. As a result the spotlight is turned towards promotion of energy production from renewable energy sources like solar, wind, tidal, geothermal etc. Taking into consideration the aforesaid concept, this paper proposes a hybrid microgrid consisting of PV-SOFC with VSI based PI controller working in an islanding mode so that voltage and frequency is maintained in their acceptable limits and the output demonstrated using Matlab/Simulink shows the efficacy of the controller in providing efficient energy which gives the lowest environmental impacts.
\end{abstract}

Keywords--- Photovoltaic (PV), Solid Oxide Fuel Cell (SOFC), Voltage Source Inverter (VSI), Proportional Integral Controller (PI), Microgrid (MG), Distributed Generators (DG).

\section{INTRODUCTION}

The current energy requirements are fulfilled using sources like coal, rock oil and natural crude oil. Typical energy systems are synchronized and thus electrical energy needs to travel more than hundreds of kilometer resulting in energy deficits and reduces the stability of the electrical system. Another downside of the traditional methodology is the discharge of tons of waste products which goes into atmosphere causing global heating [1]. The exhaustible character of the fossil energy accounts to the rising energy demands on the other "sustainable energy" based DGs, which in turn prompted analysts to make researches on renewable sources. This paved the way to satisfy energy requirement in an eco-friendly way, and to focus the production of electrical power from different nonconventional energy sources like wind, tidal, solar energy, geothermal, biofuel and so forth. These are uncontaminated cost effective and abundantly accessible in nature.

Recently these renewable energy sources are used widely along with a few others like Fuel Cells (FC) which are in the progressed formative face [2]-[4]. If exploited sufficiently, renewable source could provide enough energy for upcoming generations [5]. The most common and widely used renewable energy source is PV. It is accessible

\footnotetext{
Manuscript received September 16, 2019
}

V.P. Vinod, Research Scholar, Department of Electrical \& Electronics Engineering, Saveetha School of Engineering, SIMATS, Chennai.T.N India.(e-mail: mail2vinodvp@gmail.com)

N. Albert Singh*, Executive, Bharath Sanchar Nigam Limited, Chennai, Tamil Nadu, T.N, India. (e-mail: basisngc@gail.com) generating systems that mainly uses natural non-sustainable

everywhere and is simple to connect with power converters [6]. It is energy efficient, ecofriendly and to an extend economical. Even though PV is beneficial, the output power produced by PV is very keen on weather conditions. PV system will not produce any power during a particular time period (e.g., rainy or during the night). And all normal variation in temperature and solar irradiance induces oscillations in a PV system. And also, the generated PV energy is troublesome to store for future use [7]. Inorder to eliminate this major drawback, we have to incorporate it with an effective distributed generating unit; probably a fuel cell.

The recent researches on fuel cells provides as ample information regarding different types of fuel cells and among them Solid Oxide Fuel Cell (SOFC) is the most apt one to be associated with a PV. Therefore SOFC methodology for microgrid has been showing its potential and can be considered as an essential power supply for upcoming MG system. SOFC is usually a stagnant power source which produces electrical power from hydrogen via the process of electrolysis. The greater reliability, no noise level and no rotating parts are an additional preferred standpoint of SOFC system while compared with diesel powered generator. Principle attributes of SOFC are modularity, fuel flexibility, sensibly zero noise levels, close to zero emissions, high efficiency and high power quality. In this investigation, SOFC is chosen, since, it functions at higher temperature ranges $\left(900-1500{ }^{\circ} \mathrm{C}\right)$ [8].

The most significant issues of $\mathrm{MG}$ which creates power quality problems could be attributed to operating mode of MG. In an islanded mode, the $\mathrm{V}$ and $\mathrm{F}$ has to be selfregulated by MG, if not; the fault occurs due to the nature of the linked DG systems and the power electronics converter. In [9] $\mathrm{V}$ and $\mathrm{F}$ is regulated to control Micro Grid in an islanded mode by keeping $\mathrm{V}$ and $\mathrm{F}$ at reference values. However $\mathrm{V}$ and $\mathrm{F}$ regulator for $\mathrm{MG}$ in a self-governing mode struggles to take action to change loads, therefore [10], a master-slave control for MG is implemented. In grid mode, MG is furnished with power controllers and in autonomous mode, VSI switches to keep the MG Voltage and Frequency within the optimal level.

The controllers used in the microgrid, the criterion for sharing the power between the MG and utility grid during non-autonomous mode and its recital during self-governing mode was also analyzed in [11]. 


\section{A NEW PV-SOFC BASED HYBRID TOPOLOGY USING PI CONTROLLER FOR THE REGULATION OF VOLTAGE AND FREQUENCY PROFILE IN AN AUTONOMOUS MICROGRID}

However, these were not considered during the tuning of PI control parameters, but are essential during the change of MG working modes or load changes. In the papers [12-13], the authors attained a powerful response in the control system with Total Harmonic Distortion within the appropriate levels. On the other hand oscillation in output power exposes many technical issues like voltage instability, frequency divergence and harmonics etc. on grid side. To retain the operational $\mathrm{V}$ and $\mathrm{F}$, a proper design of controller which secure the system from instability, is vital. The PI based controller is used to regulate \&control the frequency of microgrid. The proposed PI controller is designed to manage the MG voltage and frequency when it's either selfgoverned or in load variations, thus keeping the quality of generated power. The MG model includes $8 \mathrm{~kW} \mathrm{SOFC} \mathrm{as} \mathrm{a}$ DG connected with a $100-\mathrm{kV}$ typical grid. In addition, an FFT analysis is taken to address the constancy of the system proposed. Contrasted with the traditional MPPT methods, Perturb and Observe calculation is proposed in the system to extricate the power at maximum point from the PV [14].

The Major contribution of the work is given below,

- Hybrid DC/AC microgrid (PV-SOFC) is proposed to diminish different switching transformations to enhance the system efficiency.

- To extricate the MPP from the sustainable power sources, MPPT Perturb \& Observe Method is used because of its high accuracy, efficiency \& tracking speed.

- To ensure the stable operation by analyzing the regulation of voltage and frequency, also examines the power quality by conducting THD analysis for
Phase voltage and phase current of DC/AC microgrid controlled by PI controller.

In the paper the proposed method of microgrid and mathematic modeling of PV and SOFC are discussed in section 2 Subsequently, Section 3 discusses about the proposed PI controller strategy and the obtained results and inferences are given in $4^{\text {th }}$ Section. Section 5 conveys the conclusions and also illustrates suggestions for future works.

\section{SYSTEM MODELING}

This section describes the structure of hybrid PV-SOFC Microgrid (MG), interfacing with the traditional grid. PV modelling and SOFC modelling are explained in detailed in subsequent sections.

\subsection{Proposed Microgrid system}

The methodology of hybrid Microgrid (MG) incorporating PV-SOFC connected with grid is given in Fig.1. Here a PV-SOFC microgrid is developed to validate the efficiency and effectiveness of controllers. They are coupled to the infinite bus via unidirectional boost converter (dc-dc), Voltage Source Converter (VSC) and Transformers. The loads regarded as significant and nonsignificant loads. The constant DC output voltage of PV and SOFC is set as the VSI input. The VSI converts DC supply into AC and supplies to the grid. The output parameters are maintained constant by the PI Controller. The AC voltage is managed by grid and DC voltage is managed by VSI. The terminal voltage is calculated by the $\mathrm{P} \& \mathrm{O}$ algorithm irrespective of solar irradiation.

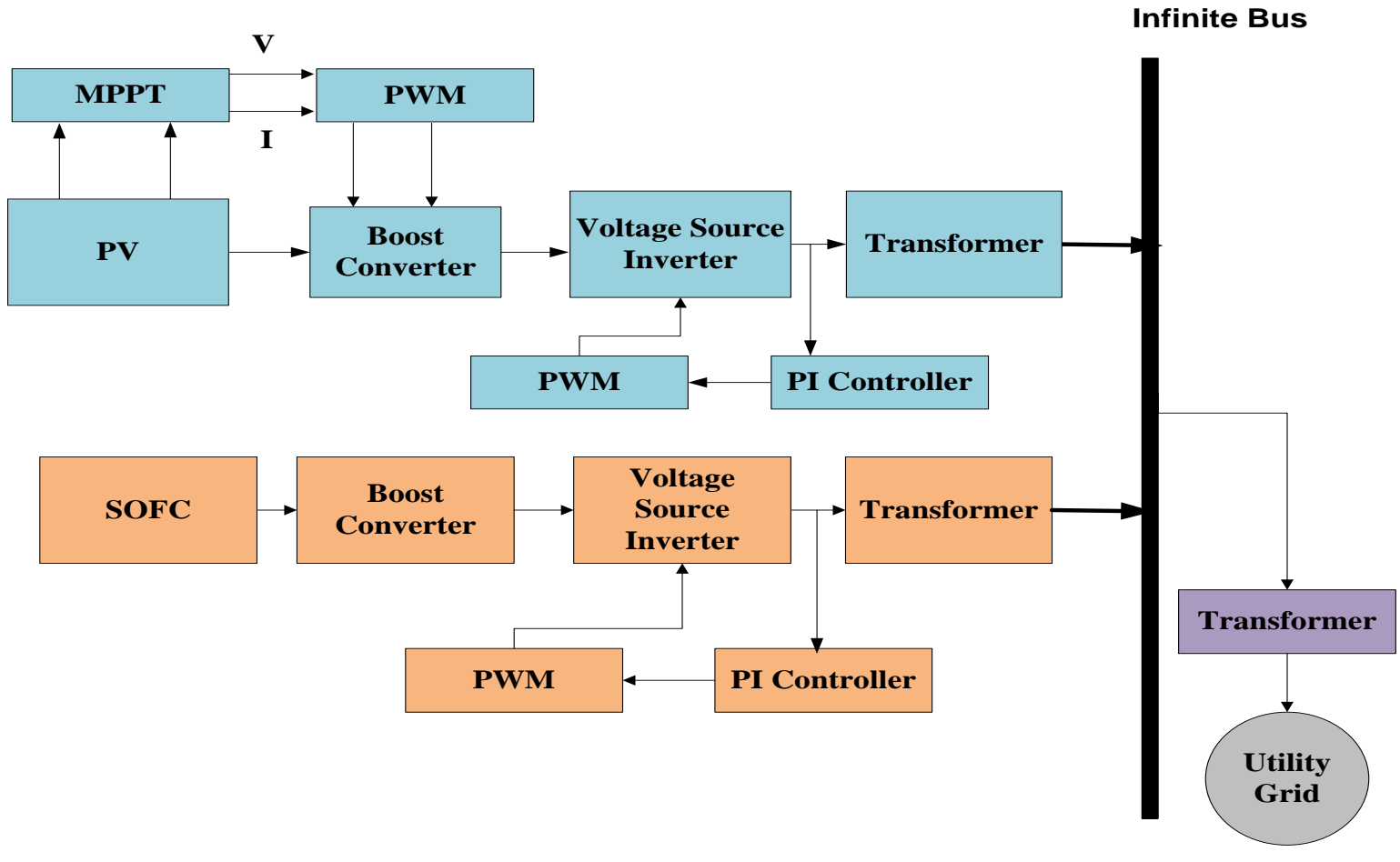

Fig. 1: PV-SOFC autonomous microgrid 
As the proposed PV-FC microgrid is working in a selfgoverning mode, the MG operation is not associated with the utility grid. The designing and implementation of different system elements and its control are briefed in the sub-sequent sections. In the manuscript the $\mathrm{PV}$ is demonstrated as a current source linked to an ideal diode. The SOFC can be a dynamic model describing correlation between fuel input and output voltage.

\subsection{Modeling of $P V$}

PV generators can be a current source or a voltage source however it can be designed as current generators with dependent voltage sources. When a solar cell is bare to sunlight, a DC current is produced and is proportional to the solar radiations directly. Figure. 2 demonstrate the electrical equivalent circuit of a single solar module. The detailed evaluations on PV modeling, challenges and its applications are addressed in detail [15-17].

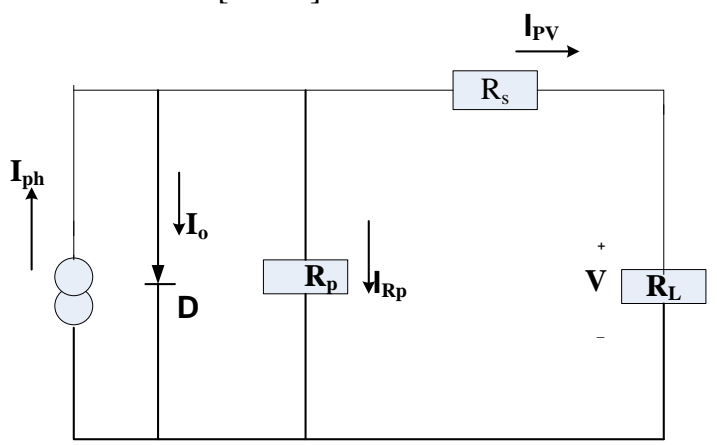

Fig. 2: PV cell, Equivalent Circuit

The different parameters of the PV cells are:

Where, $\left(I_{p h}\right)$ denotes the current output of PV cell $(A)$, Rsdenotes the series Resistance $(\Omega), \quad R_{p}$ denotes the parallel Resistance $(\Omega)$,Iodenotes the Diode current $(A)$, Ipvdenotes the PV Current output $(A)$, and $(V)$ denotes the PV voltage output $(V)$ [18 \& 19].

Table 1: Electrical characteristics of PV module

\begin{tabular}{|l|c|}
\hline \multicolumn{1}{|c|}{ Description } & Rating \\
\hline Power at Maximum Power Point & $210 \mathrm{~W}$ \\
\hline Open circuit voltage $\left(V_{\text {oc }}\right)$ & $52.5 \mathrm{~V}$ \\
\hline Short circuit current $\left(I_{s c r}\right)$ & $5.75 \mathrm{~A}$ \\
\hline Number of series cells $N_{s}$ & 36 \\
\hline Number of parallel cells $N_{p}$ & 1 \\
\hline Voltage at MPP & $42 \mathrm{~V}$ \\
\hline Current at MPP & $5 \mathrm{~A}$ \\
\hline
\end{tabular}

In Fig.2, the PV module photon generated current $I_{p h}$ is significant by,

$$
I_{p h}=\left[I_{S C r}+K_{i}\left(T_{k}-T_{r e f}\right)\right] \times \frac{\lambda}{1000}
$$

The reverse saturation current of diode $I_{r s}$ is represented by Eq. (2).

$$
I_{r s}=\frac{I_{S c r}}{\left[\exp \left(\frac{q V_{O C}}{N_{S K A T}}\right)-1\right]}
$$

Where $q$ isthe electron charge $(1.6 \times 10-19 C)$, $k$ represents the Boltzmann constant $(1.3805 \times 10-23 \mathrm{~J} / \mathrm{K})$, and $A$ denotes the diode ideality factor (1.6).Equation (3) gives module saturation current $\mathrm{I}_{0}$,

$$
\mathrm{I}_{0}=\mathrm{I}_{\mathrm{rs}}\left[\frac{\mathrm{T}}{\mathrm{T}_{\mathrm{r}}}\right]^{3} \exp \left[\frac{\mathrm{q} * \mathrm{E}_{\mathrm{go}}}{\mathrm{BK}}\left\{\frac{1}{\mathrm{~T}_{\mathrm{r}}}-\frac{1}{\mathrm{~T}}\right\}\right]
$$

Where, $E_{g o}$ denotes the band gap energy of the semiconductor $(E g o=1.11 \mathrm{eV}$ for the polycrystalline $\mathrm{Si}$ at $25 \mathrm{C}$ ). Equation (4) gives the output current $\mathrm{I}_{\mathrm{pV}}$,

$$
\begin{aligned}
& \mathrm{I}_{\mathrm{PV}}=\mathrm{N}_{\mathrm{p}} * \mathrm{I}_{\mathrm{ph}}-\mathrm{N}_{\mathrm{p}} * \mathrm{I}_{0}\left[\exp \left(\frac{\mathrm{q} * \mathrm{~V}_{\mathrm{PV}}+\mathrm{I}_{\mathrm{PV}} \mathrm{R}_{\mathrm{S}}}{\mathrm{N}_{\mathrm{S}} \mathrm{KAT}}\right)-1\right]-\mathrm{V}_{\mathrm{PV}}+\left(\mathrm{I}_{\mathrm{PV}} \mathrm{R}_{\mathrm{S}}\right) / \mathrm{R}_{\mathrm{Sh}}(4) \\
& \mathrm{I}_{\mathrm{PV}}=\mathrm{N}_{\mathrm{p}} * \mathrm{I}_{\mathrm{Ph}}-\mathrm{N}_{\mathrm{p}} * \mathrm{I}_{\mathrm{O}}\left[\exp \left(\frac{\mathrm{q} * \mathrm{~V}_{\mathrm{PV}}+\mathrm{I}_{\mathrm{PV}} \mathrm{R}_{\mathrm{S}}}{\mathrm{N}_{\mathrm{S}} \mathrm{KAT}}\right)-1\right]
\end{aligned}
$$

Hence,

$$
\mathrm{I}_{\mathrm{pV}}=\mathrm{I}_{\mathrm{ph}}-\mathrm{I}_{\mathrm{O}}
$$

\subsection{Modeling of SOFC}

SOFC is a high temperature withstanding fuel cell with metallic oxide solid ceramic electrolyte. SOFC generally uses an assortment of carbon monoxide and hydrogen created by internally reforming air and hydrocarbon fuel as an oxidizing agent in the FC [20].

Mostly used electrolyte for SOFC is Yttria-stabilized zirconia (YSZ) for the reason that it's high chemical, pure ionic conductivity and thermal stability [21].

The SOFC modeling is designed on following suppositions:

i) Invariant FC temperature, ii)FC gases are ideal, iii) FC is reformed by hydrogen and air, iv) In the interior of the electrodes only one pressure is mentioned, and v) SOFC designed according to Nernst's equation,

The voltage over the FC stack $\left(V_{f c}\right)$ given by (7),

$$
V_{f C}=N_{o}\left(E_{o}+\frac{R T}{2 F} \ln \left(\frac{P H_{2} P_{2}{ }^{0.5}}{P H_{2} O}\right)\right)-r I_{f C} \text { (7) }
$$

Where, $E_{o}$ denotes standard reversible cell potential (V), $N_{o}$ denotes quantity of cells in stack, $r$ is the internal resistance $(\Omega), p 02, p H 2 O \& p H 2$ are the partial pressures of oxygen, water and hydrogen respectively. The dynamics of SOFC are mentioned by (7)-(12),

$$
\begin{aligned}
& q H_{2}{ }^{i n}=\frac{1}{1+s T_{f}}\left[\frac{2 K r}{U_{o p t}} I_{F C}\right] \\
& q \mathrm{O}_{2}{ }^{i n}=\frac{1}{r H O} q \mathrm{H}_{2}{ }^{i n} \\
& P H_{2}=\frac{1 / k H_{3}}{1+s t H_{3}}\left[q H_{2}^{i n}-2 K r I_{F C}\right] \\
& \mathrm{PO}_{2}=\frac{{ }^{1} / \mathrm{kO}_{3}}{1+s t O_{2}}\left[\frac{1}{r H O} q H_{2}{ }^{i n}-K r I_{F C}\right] \\
& \mathrm{PH}_{2} \mathrm{O}=\frac{{ }^{1 / \mathrm{kH}_{3} \mathrm{O}}}{1+\mathrm{stH_{2 } O}} 2 \mathrm{Kr} I_{\mathrm{FC}}
\end{aligned}
$$




\section{A NEW PV-SOFC BASED HYBRID TOPOLOGY USING PI CONTROLLER FOR THE REGULATION OF VOLTAGE AND FREQUENCY PROFILE IN AN AUTONOMOUS MICROGRID}

Where, $q \mathrm{O}_{2}, q \mathrm{H}_{2}$ gives oxygen and hydrogen flow rate ( $\mathrm{mol} / \mathrm{s}$ ), $\mathrm{Ko}_{2}, \mathrm{kH}_{2}, \mathrm{kH}_{2} \mathrm{O}$ are the valve molar constant for oxygen, hydrogen and Water ( $\mathrm{kmol} / \mathrm{s} \mathrm{atm}$ ), $t \mathrm{H}_{2}, \mathrm{to}_{2}, t \mathrm{H}_{2} \mathrm{O}, t f$ is the time response for hydrogen, Oxygen, water and fuel(sec), Uopt is the optimum fuel utilization, $\mathrm{rHO}$ is proportion of hydrogen to oxygen, $\mathrm{Kr}$ is a constant $(\mathrm{kmol} / \mathrm{s} \mathrm{A})$.

Table 1I: Electrical parameters of the SOFC module

\begin{tabular}{|l|l|}
\hline Description & Rating \\
\hline Absolute temperature & $1273 \mathrm{~K}$ \\
\hline Initial Current (A) & $100 \mathrm{~A}$ \\
\hline Number of cells in series & 450 \\
\hline Faraday's Constant (C/kmol) & $96.487 \mathrm{e} 6$ \\
\hline Universal Gas constant (J/kmol K) & 8314 \\
\hline Ideal standard potential (V) & $1.18 \mathrm{~V}$ \\
\hline Output Voltage & $330 \mathrm{~V}$ \\
\hline Output Current & $20 \mathrm{~A}$ \\
\hline
\end{tabular}

\section{PROPOSED METHODOLOGY}

The proposed control strategy for a VSI based PI controller is as follows. The error can be calculated by evaluating the output of VSI with constant reference voltage. The amplifier amplify the error signal and gives it to the PI Controller which creates the control signal based on varying the duty cycle of regulator switch of VSI which aids to keep the constant output voltage with respect of input voltage. The processing of error signal could be very complex due to the delays in the system. The stability of the system can be improved by tuning the controller parameters $\mathrm{K}_{\mathrm{p}}$ and $\mathrm{K}_{\mathrm{i}}$ and thus the error signal is processed. Fig.3 shows Simulink diagram of $P I$ controller used in the microgrid for $\mathrm{V}$ and $\mathrm{F}$ control.

The reference values of current are taken as $i_{d}^{*}$ and $i_{q}^{*}$ from the outer current loop of the system [22].

$$
\begin{gathered}
i_{d}^{*}=\left(V_{\text {ref }}-V\right)\left(K_{p}+\frac{K_{i}}{s}\right) \\
i_{q}^{*}=\left(f_{\text {ref }}-f\right)\left(K_{p}+\frac{K_{i}}{s}\right)
\end{gathered}
$$

For improving the system response, proper utilization of inverter current loop and the feed forward voltage loop of the grid is required. In a synchronously rotating $\mathrm{d}_{\mathrm{q}}$ frame by taking voltage as the reference output of the controller straggled by Park's inverse and Clarke's transformation, controller results yields the reference voltage signal in $\alpha \beta$ axis. PWM technique triggers VSI and the THD values are maintained within limits. Expressions for the reference voltage in synchronous 'dq' frame is,

$$
\begin{gathered}
{\left[\begin{array}{l}
v_{d}^{*} \\
v_{q}^{*}
\end{array}\right]=\left[\begin{array}{cc}
-K_{P} & -\omega_{L S} \\
\omega_{L S} & -K_{P}
\end{array}\right]\left[\begin{array}{l}
i_{d} \\
i_{q}
\end{array}\right]+\left[\begin{array}{cc}
K_{P} & 0 \\
0 & K_{P}
\end{array}\right]\left[\begin{array}{l}
i_{d}^{*} \\
i_{q}^{*}
\end{array}\right]+\ldots} \\
\ldots\left[\begin{array}{cc}
K_{i} & 0 \\
0 & K_{i}
\end{array}\right]\left[\begin{array}{l}
X_{d} \\
X_{q}
\end{array}\right]\left[\begin{array}{l}
v_{s d} \\
v_{s q}
\end{array}\right]
\end{gathered}
$$

Using inverse Park's transformation and Clarke's transformation Eq (15) can be converted into 'abc' frame and ' $\alpha \beta$ ' frame respectively,

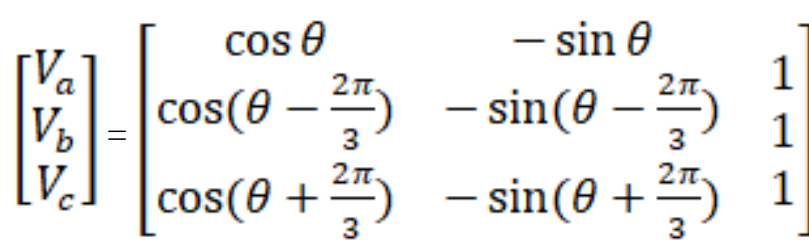

(16)

$$
\left[\begin{array}{l}
V_{\alpha} \\
V_{\beta} \\
V_{0}
\end{array}\right]=\frac{2}{3}\left[\begin{array}{l}
V_{a} \\
V_{b} \\
V_{c}
\end{array}\right]\left[\begin{array}{ccc}
1 & -1 / 2 & -1 / 2 \\
0 & \sqrt{3} / 2 & -\sqrt{3} / 2 \\
1 / 2 & 1 / 2 & 1 / 2
\end{array}\right]
$$

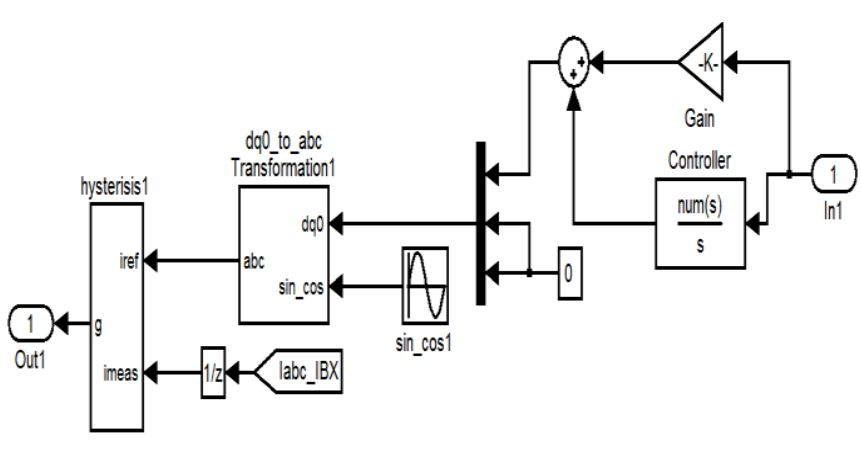

Fig.3: Simulink diagram of Proposed PI controller

\section{RESULTS AND DISCUSSION}

The proposed PV/SOFC microgrid system includes 88 $\mathrm{kW} \mathrm{PV}$ and $8 \mathrm{~kW}$ SOFC the battery time constant is considered as 5 s for running the simulation.

The output shows the efficiency of the proposed PI Controller, which effectively regulates frequency and voltage.

Initially the model is set to operate in the grid mode. At $0.5 \mathrm{~s}$, the islanding operation of the MG takes place. System is controlled by conventional PI with fixed gain values for PV $\left(\mathrm{K}_{\mathrm{p}}=1.059, \mathrm{~K}_{\mathrm{i}}=3005.8\right)$ and for SOFC $\left(\mathrm{K}_{\mathrm{p}}=1.082\right.$, $\mathrm{K}_{\mathrm{i}}=3012.2$ ).

This tuned values instigate the system from the reduction in the voltage drop and the uncertainty in frequency owing to abrupt transformation in operation mode. When the system reaches at $\mathrm{t}=0.5 \mathrm{~ms}$, the voltage produced by the DG has less oscillations and it resolves within $2 \mathrm{~ms}$.

In addition, for some sensitive loads, the voltage overshoot throughout switching phase cannot be in desirable condition.

In this instance PI with VSI offers less overshoot in comparison with classical control methods discussed in literature review.

Similarly, the frequency deviation is shown in Fig.4; however, frequency gets stabled more rapidly in with the PI regulator as restored the frequency level within the satisfactory boundaries. 


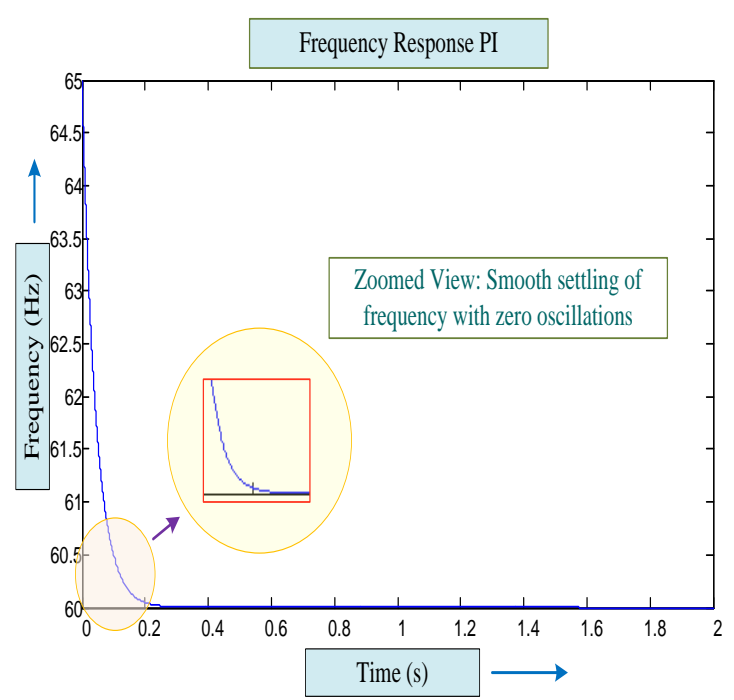

Fig.4: Regulated Frequency of Microgrid

\subsection{Dynamic and steady-state response}

Dynamic or steady state recital of the control strategy can be explained as, the inverter output current is alienated into two stages. MG is shifted to islanding at $\mathrm{t}=0.4 \mathrm{~s}$ initially, then at $\mathrm{t}=0.6 \mathrm{~s}$ gradual increase in load takes place. Fig. 5 and 6 shows microgrid output voltage and current under PI strategy. Here, within two milliseconds current attains short transient state and then steady state is attained at $0.6 \mathrm{~s}$. The output waveforms of microgrid voltage and current shown are perfectly sinusoidal and have less harmonic contents.

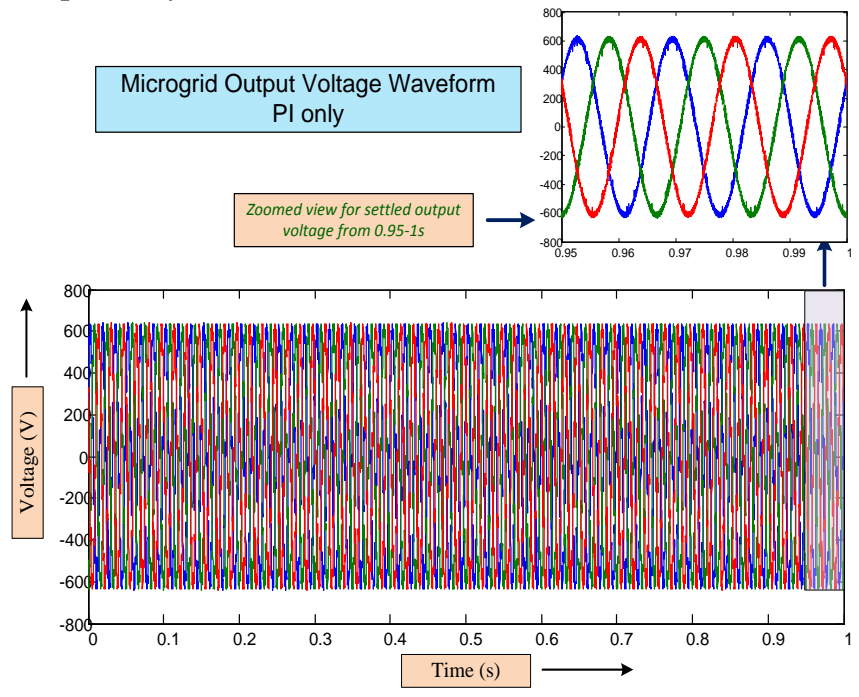

Fig. 5: Microgrid Output Voltage waveform

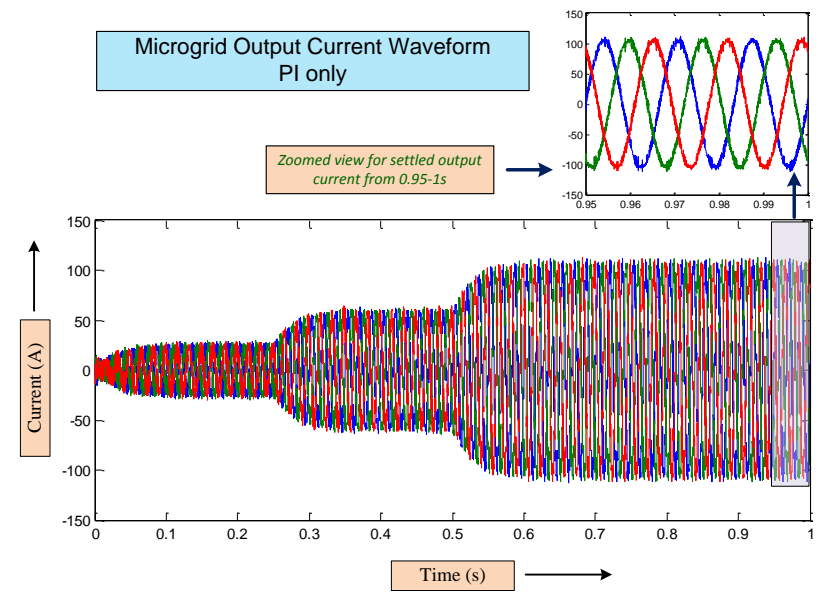

Fig. 6: Microgrid Output Current waveform
Correspondingly, Fig.7 gives the THD spectrum for both microgrid voltage and current. The values are $1.23 \%$ and $1.43 \%$ respectively and are significant. Table III provides THD values of odd harmonics for the three phases and are under the limits mentioned in the relevant standard of IEEE1547-2003[24].

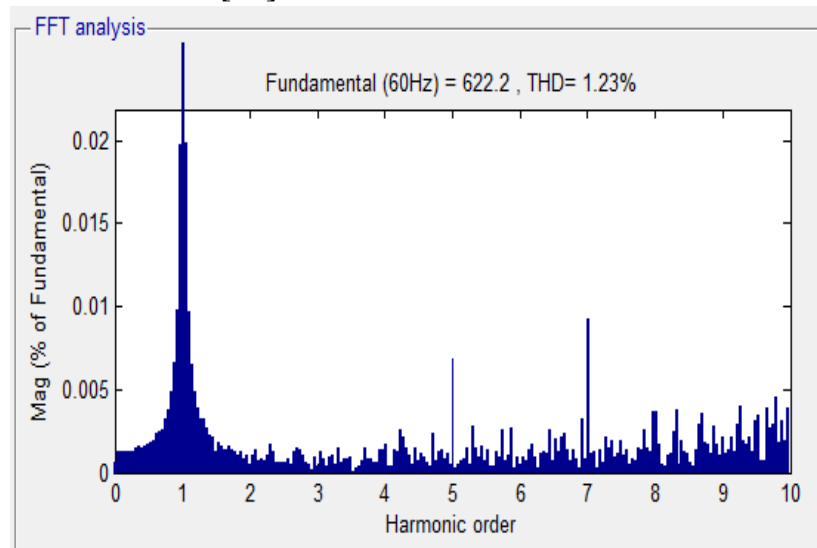

(a)

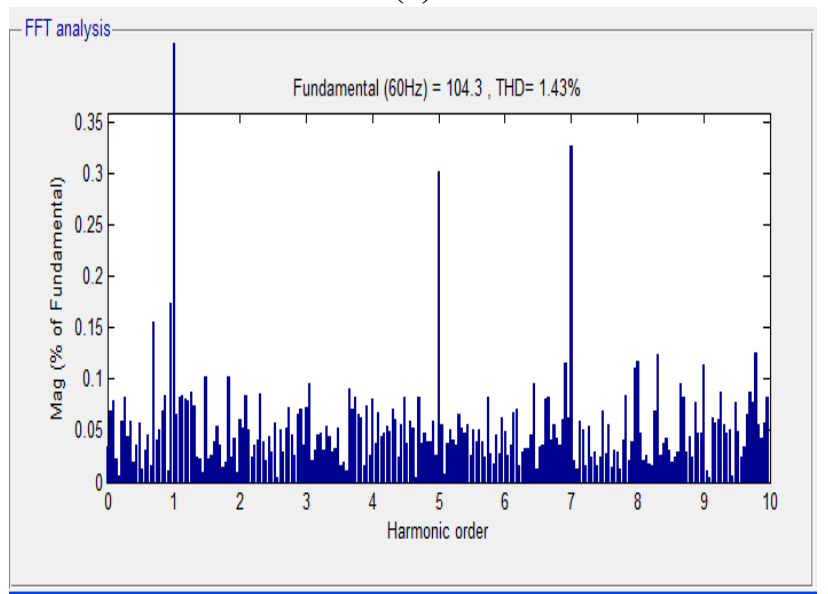

(b)

Fig.7: THD spectrum of MG a) Voltage b) Current Table III: THD Analysis for MG Phase Voltage and Current

\begin{tabular}{|c|c|c|c|c|c|c|}
\hline \multirow{2}{*}{$\begin{array}{c}\text { THD } \\
\text { Level }\end{array}$} & \multicolumn{7}{|c|}{ THD (\%) } \\
\cline { 2 - 7 } & \multicolumn{2}{|c|}{ Phase Voltage (1.23\%) } & \multicolumn{2}{c|}{ Phase Current (1.43\%) } \\
\cline { 2 - 7 } & $\mathbf{a}$ & $\mathbf{b}$ & $\mathbf{c}$ & $\mathbf{a}$ & $\mathbf{b}$ & $\mathbf{c}$ \\
\hline 3rd & 0.01 & 0.01 & 0.01 & 0.07 & 0.05 & 0.12 \\
\hline 5th & 0.04 & 0.05 & 0.05 & 0.3 & 0.31 & 0.35 \\
\hline 7th & 0.06 & 0.05 & 0.06 & 0.33 & 0.28 & 0.3 \\
\hline 9th & 0.01 & 0.02 & 0.03 & 0.11 & 0.01 & 0.12 \\
\hline
\end{tabular}

\section{CONCLUSION}

Different control strategies for microgrids are attaining highest attention in recent years. A smart control technique of PI with VSI based MG has introduced in this context. The goals of such methods are to control $\mathrm{V}$ and $\mathrm{F}$ in an islanded hybrid microgrid system. A PV-SOFC system is modelled and is demonstrated in MATLAB/SIMULINK software. The distributed generators coupled with VSI and PI controller regulate the frequency and voltage of the system under self-governing mode. 


\section{A NEW PV-SOFC BASED HYBRID TOPOLOGY USING PI CONTROLLER FOR THE REGULATION OF VOLTAGE AND FREQUENCY PROFILE IN AN AUTONOMOUS MICROGRID}

The system response under dynamic and steady state has been evaluated. The quality of the power supplied by the distributed generators to the microgrid at the common point of coupling is examined by conducting THD analysis. The proposed controller with PI shows an excellent response in controlling the microgrid parameters. The VSI-PI method also obtains acceptable Total Harmonic Distortion level. Hence, PI controller strategy is very apt for microgrid control operations and interfacing of different DG units can be considered while solving power allocation issues. To validate the functionality of proposed system, the conventional PI controller can be tuned for better gain values with different intelligent optimization techniques and are recommended for future work.

\section{REFERENCES}

1. Bull SR. Renewable energy today and tomorrow. Proceedings of the IEEE. 2001 Aug;89(8):1216-26.

2. Zahran M. Photovoltaic hybrid systems reliability and availability. Journal of Power Electronics. 2003;3(3):145-50.

3. Hassan SZ, Mumtaz S, Kamal T, Khan L. Performance of grid-integrated photovoltaic/fuel cell/electrolyzer/battery hybrid power system. InPower Generation System and Renewable Energy Technologies (PGSRET), 20152015 Jun 10 (pp. 1-8). IEEE.

4. Kamal T, Hassan SZ, Li H, Mumtaz S, Khan L. Energy management and control of grid-connected wind/fuel cell/battery Hybrid Renewable Energy System. In Intelligent Systems Engineering (ICISE), 2016 International Conference on 2016 Jan 15 (pp. 161-166). IEEE.

5. Ahmed NA, Miyatake M, Al-Othman AK. Power fluctuations suppression of stand-alone hybrid generation combining solar photovoltaic/wind turbine and fuel cell systems. Energy Conversion and Management. 2008 Oct 1;49(10):2711-9.

6. Tian W, Wang Y, Ren J, Zhu L. Effect of urban climate on building integrated photovoltaics performance. Energy Conversion and Management. 2007 Jan $1 ; 48(1): 1-8$

7. Mitchell K, Nagrial M, Rizk J. Simulation and optimisation of renewable energy systems. International Journal of Electrical Power \& Energy Systems. 2005 Mar 1;27(3):177-88.

8. Das T, Snyder S. Adaptive control of a solid oxide fuel cell ultra-capacitor hybrid system. IEEE Transactions on Control Systems Technology. 2013 Mar;21(2):372-83.

9. Barsali S, Ceraolo M, Pelacchi P, Poli D. Control techniques of dispersed generators to improve the continuity of electricity supply. In Power Engineering Society Winter Meeting, 2002. IEEE 2002 (Vol. 2, pp. 789-794). IEEE.

10. Chen X, Wang YH, Wang YC. A novel seamless transferring control method for microgrid based on master-slave configuration. In ECCE Asia Downunder (ECCE Asia), 2013 IEEE 2013 Jun 3 (pp. 351-357). IEEE.

11. Janjornmanit S, Premrudeepreechacharn S. A power sharing control for microgrids based on extrapolation of injecting power and power-angle control. Turkish Journal of Electrical Engineering \& Computer Sciences. 2017 Apr 10;25(2):689-704.

12. Khorramabadi SS, Bakhshai A. Critic-based self-tuning PI structure for active and reactive power control of VSCs in microgrid systems. IEEE Transactions on smart grid. 2015 Jan;6(1):92-103.
13. Nandar CS. Robust PI control of smart controllable load for frequency stabilization of microgrid power system. Renewable energy. 2013 Aug 1;56:16-23.

14. Subudhi B, Pradhan R. A comparative study on maximum power point tracking techniques for photovoltaic power systems. IEEE Transactions on sustainable energy. 2013 Jan;4(1):89-98.

15. Pillai DS, Rajasekar N. Metaheuristic algorithms for PV parameter identification: A comprehensive review with an application to threshold setting for fault detection in PV systems. Renewable and Sustainable Energy Reviews. 2018 Feb 1;82:3503-25.

16. Ram JP, Manghani H, Pillai DS, Babu TS, Miyatake M, Rajasekar N. Analysis on solar PV emulators: A review. Renewable and Sustainable Energy Reviews. 2018 Jan 1;81:149-60.

17. Pillai DS, Sahoo B, Ram JP, Laudani A, Rajasekar N, Sudhakar N. Modellingof Organic Photovoltaic Cells Based on an Improved Reverse Double Diode Model. Energy Procedia. 2017 Jun 1;117:1054-61.

18. Pillai DS, Ram JP, Nihanth MS, Rajasekar N. A simple, sensorless and fixed reconfiguration scheme for maximum power enhancement in PV systems. Energy Conversion and Management. 2018 Sep 15;172:402-17.

19. Pillai DS, Rajasekar N, Ram JP, Chinnaiyan VK. Design and testing of two phase array reconfiguration procedure for maximizing power in solar PV systems under partial shade conditions (PSC). Energy Conversion and Management. 2018 Dec 15;178:92-110.

20. Irshad M, Siraj K, Raza R, Ali A, Tiwari P, Zhu B Rafique A, Ali A, Kaleem Ullah M, Usman A. A brief description of high temperature solid oxide fuel cell's operation, materials, design, fabrication technologies and performance. Applied Sciences. 2016 Mar 9;6(3):75.

21. Singhal SC. Advances in solid oxide fuel cell technology. Solid state ionics. 2000 Nov 1;135(1-4):30513.

22. Qazi SH, Mustafa MW, Hussain N, Sultana U Performance evaluation of PI and PI-PSO in improving power quality of an autonomous microgrid.

23. Kwon BH, Min BD, Youm JH. An improved spacevector-based hysteresis current controller. IEEE Transactions on Industrial Electronics. 1998 Oct;45(5):752-60.

24. IEEE Standards Coordinating Committee. IEEE Standard for Interconnecting Distributed Resources with Electric Power Systems. IEEE Std1547-2003. 2009. 